\title{
A comparison of chromosome instability in cell suspensions of diploid, tetraploid and hexaploid wheats
}

\author{
MARK WINFIELD, MICHAEL R. DAVEY* \& ANGELA KARP \\ Department of Agricultural Sciences, University of Bristol, AFRC Institute of Arable Crops Research, Long Ashton \\ Research Station, Long Ashton, Bristol BS18 9AF, and *Department of Life Science, University of Nottingham, \\ Nottingham NG7 2RD, U.K.
}

\begin{abstract}
Chromosome instability was monitored through time in cell suspensions of the diploids Triticum tauschii (the $\mathrm{D}$ genome donor) and T. monococcum (the A genome donor), the tetraploids, $T$. durum and $T$. dicoccum (both $\mathrm{AABB}$ ) and in the cultivars Copain and Sicco of hexaploid (AABBDD) breadwheat ( $T$. aestivum). Differences in stability were observed between the different ploidy levels and between species within the ploidy levels. The diploids were most stable, particularly $T$. tauschii, and the hexaploids were least stable. Instability was greatest in all the lines during the first months of culture. In all but one line, very few structural aberrations were observed, even after many months in culture. Morphogenetic capacity was lost in all lines, even though some retained high proportions of euploid cells. The relevance of these results is discussed in relation to the regeneration of breadwheat from protoplasts.
\end{abstract}

Keywords: chromosomes, suspension, cultures, wheat.

\section{Introduction}

It has been known for some time that chromosome instability can occur in plant cells that are cultured as callus or cell suspensions. Early studies in tobacco showed that populations of cultured cells were a heterogenous mixture, often with high incidences of aneuploidy, polyploidy and structural rearrangements (Murashige \& Nakano, 1967). As more species were introduced into culture, in-vitro chromosome instability was recognized as a general phenomenon of plant cell cultures (for review see Bayliss, 1980).

A wider significance of chromosome variation in culture became apparent when plant regeneration was achieved from cultured cells and the regenerated plants were not true-to-type, as expected for asexual reproduction, but were subject to 'somaclonal' variation (Larkin \& Scowcroft, 1981). In some systems the occurrence of cytological abnormalities during the culture phase was found to be a major cause of phenotypic variation in the regenerants, particularly in protoplastderived plants where the frequency of numerical and structural chromosome variation could be high (Karp et al., 1982). In addition, it became clear that chromo-

Correspondence: A. Karp. some instability had an influence on the ability of cultures to undergo regeneration; non-morphogenetic cell lines were characterized by greater levels of instability than morphogenetic lines and loss of morphogenetic potential could result from an increase in cytological aberrations (Karp, 1991).

In the Gramineae it is not easy to regenerate whole plants from protoplasts and, to date, this has only been achieved by first establishing morphogenetic cell suspensions from which protoplasts are then isolated. This dependence on an in-vitro period results in cereal regeneration from protoplasts being subjected to the problems of cytological instability. In rice and maize, regeneration from protoplasts is possible but still difficult to achieve, and the regenerated plants may show phenotypic abnormalities and reduced fertility (Abdullah et al., 1989). There have been isolated reports in wheat of whole plant regeneration but a reproducible method has not yet been established (Harris et al., 1988; Vasil et al., 1990; Chang et al., 1991; He et al., 1992; Li et al., 1992).

Breadwheat (Triticum aestivum) is an allohexaploid possessing the three homoeologous genomes, A, B and D. As it is both hybrid and polyploid it might be expected to be more subject to cytological instability in cell cultures than rice and maize, which are both 
diploids containing only one genome. An earlier study of cell suspensions and protoplasts of wheat with limited regenerative capacity showed that substantial chromosome loss and karyotypic restructuring had occurred, suggesting that morphogenesis from these lines was limited by problems in maintaining chromosome stability (Karp et al., 1987).

Previous studies have demonstrated the effects of different media and culture conditions on the morphogenetic potential of wheat cell lines (Hashim et al., 1991) and provided evidence that morphogenetic potential is under genetic control (Lazar et al., 1983; Galiba et al., 1986; Higgins \& Mathias, 1987). However, there have been no attempts to determine whether the predisposition of wheat to chromosome instability in culture relates to its allohexaploid nature. In order to address this question, cell lines have been initiated from the diploids $T$. tauschii, synonym Aegilops squarrosa, (the $\mathrm{D}$ genome donor) and $T$. monococcum (the A genome donor), and the tetraploids T. durum and T. dicoccum (both AABB) and their cytological behaviour has been compared with that of a line of hexaploid breadwheat ( $T$. aestivum $\mathrm{cv}$. Sicco; AABBDD) initiated at the same time. Longterm cell suspensions of these five species have been maintained and analysed cytologically to produce a picture of the importance of ploidy and genome composition on the stability of cell lines cultured in vitro.

\section{Materials and methods}

\section{Cell suspensions}

Seeds of the five Triticum species, T. tauschii, T. monococcum, $T$. dicoccum, $T$. durum cv. Creso and $T$. aestivum cv. Sicco, were supplied by Mr S. M. Reader, Institute of Plant Science Research, Norwich, U.K. These were grown to maturity in a controlled environment room (16-h photoperiod of $275 \mu \mathrm{E} \mathrm{m}^{-2} \mathrm{~s}^{-1}$ provided by $125 \mathrm{~W}$ white fluorescent tubes and $25 \mathrm{~W}$ tungsten bulbs; day: $20^{\circ} \mathrm{C}$ night: $16^{\circ} \mathrm{C}$,). Callus was initiated from immature embryos according to Maddock et al., 1983, although with $2 \mathrm{mg} \mathrm{l}^{-1}$ 2,4-D and no coconut milk. After 28 days, all the callus was transferred into liquid MS (Murashige \& Skoog, 1962) medium containing $5 \mathrm{mg} 1^{-1}$ 2,4-D. Suspensions were subcultured every 7 days. After 4 and 18 months; samples of cell suspensions were transferred to two different regeneration media; (i) MS medium with 0.25 $\mathrm{mg} \mathrm{l}^{-1} 2,4-\mathrm{D}$, and (ii) MS medium with $1 \mathrm{mg} \mathrm{l}^{-1}$ each of 3-indoleacetic acid (IAA) and zeatin, known to induce shoot formation from wheat callus (Vasil et al., 1990). Both media contained $30 \mathrm{~g} \mathrm{I}^{-1}$ sucrose and were solidified with $8 \mathrm{~g}^{-1}$ Oxoid agar.

\section{Cytological procedures}

Samples were taken from the cell suspensions at 4-6 months, 12-15 months and 30-33 months, after initiation. These were pretreated and fixed as described by Karp \& Maddock (1984) except that a 0.001 per cent solution of $\alpha$-bromonaphthelene (1 per cent $\alpha$ bromonaphthelene solution in alcohol diluted 1 in 1,000 with distilled water) was used rather than a saturated solution. Squash preparations were made from small individual cell clumps. A minimum of 50 cells were examined per culture (between 6 and 10 slides). All photographs were taken using a Zeiss Photomicroscope.

\section{Results}

\section{Cell suspensions}

The five cell suspensions were distinct from each other in appearance and in growth characteristics. The suspension of $T$. tauschii was composed of large, dense, slow-growing colonies, approximately $1-5 \mathrm{~mm}$ in diameter. After about 24 months in culture the cell clumps became brown and died. The T. monococcum suspension was also composed of large dense colonies which were slow growing and, initially, of a similar size to those of $T$. tauschii. However, over a period of several months in culture the colonies fragmented and became smaller. The suspensions of the other three species were finer and faster growing. The suspensions of $T$. aestivum and $T$. durum had a tendency to produce an abundance of mucilage and slough off large, vacuolated cells into the medium. In consequence, after 1 week in culture the suspensions were often cloudy. $T$. aestivum was distinct in that, at intervals, many of the colonies produced roots giving the suspension the appearance of being composed of star-shaped clumps. These clumps often had a small dark, possibly necrotic, centre. Inspection with a binocular microscope showed the colonies of $T$. aestivum to be less dense than those of $T$. durum and to be bounded by a fine lace of tissue. The suspension of $T$. dicoccum was free of any mucilage and was composed of colonies about 2-3 $\mathrm{mm}$ in diameter which were slower growing than those of $T$. aestivum and T. durum.

Although the callus used to initiate all the suspensions was morphogenetic (J.-W. Bang, unpublished results), when samples of the suspensions were plated on regeneration media at 4 and 18 months shoot regeneration was not obtained. However, on both regeneration media small, dark green areas developed on some of the calli of $T$. durum. Cell clumps of $T$. aestivum developed an abundance of watery roots on both media. 


\section{Cytology}

Differences in chromosome stability were observed among the six suspensions. The diploid lines were the most stable and the hexaploid the least stable but differences were also observed between species of the same ploidy.

The cell suspension of $T$. tauschii showed very little instability throughout the period of study and after 14 months in culture 82 per cent of cells counted had an apparently normal karyotype (Fig. 1). In both the 6and 14-month samples a small percentage of cells were tetraploid. There were also some aneuploid cells; this was most evident at 6 months when 36 per cent of cells counted had the aneuploid constitution of $2 n-1=13$. Chromosome counts differed between slides; of 12 slides prepared only two possessed aneuploid cells.

The T. monococcum suspension was studied for only 12 months. During the first 5 months in culture this suspension was very stable; 97 per cent of cells having the normal chromosome number (Figs 1 and 5a). After 12 months 71 per cent of cells had 14 chromosomes and the suspension contained colonies of three distinct types; some colonies were composed of a mixture of cells with 14 and 28 chromosomes while other colonies were composed exclusively of cells of only one ploidy, either diploid or tetraploid.

The cell suspension of $T$. dicoccum was also fairly stable. Interestingly, a greater proportion of cells with the expected chromosome number $(2 n=28)$ were present after the longest period in culture; only 55 per cent of cells had 28 chromosomes after 4 months while 76 per cent of cells had 28 chromosomes after 31 months (Fig. 2). At 4 months, 23 per cent of cells had more than 50 chromosomes; 15 per cent of the total count having the octaploid constitution of 56 . This population of cells was not recorded after 31 months in culture. As in T. tauschii, the cells with different chromosome numbers were not evenly distributed among the slides preparations. Twelve slides were prepared and counts from 66 cells made. On eight of these 12 slides only cells with 29 or less chromosomes were observed, and on three slides only cells with more than 50 chromosomes were counted. One slide contained a mixture of cells with chromosome numbers ranging from 25 to 59 .

T. durum was more unstable than T. dicoccum and the two diploids. There was an initial period of stability, with 92 per cent of cells counted possessing 28 chromosomes after 6 months in culture, but, after this period, the line became very unstable. At 15 months a distinctly mixed population existed, cells with 25,26 , 27 and 28 chromosomes being almost equally abundant (Fig. 2). Interestingly, at 32 months the majority of cells had 27 chromosomes (Fig. 5b), although the population contained cells which ranged in their chromosome number from 12 to 52 .

The cell line of T. aestivum was very unstable during its first 10 months in culture (Fig. 3). After only 6 months, cells ranged in chromosome number from 27 to 45 with only 34 per cent having 42 chromosomes. At 15 months the population mode was 37 and,
Fig. 1 Histograms of chromosome number per cell in the two diploid Triticum species; based on a minimum of 50 counts. Triangle indicates the euploid chromosome number.

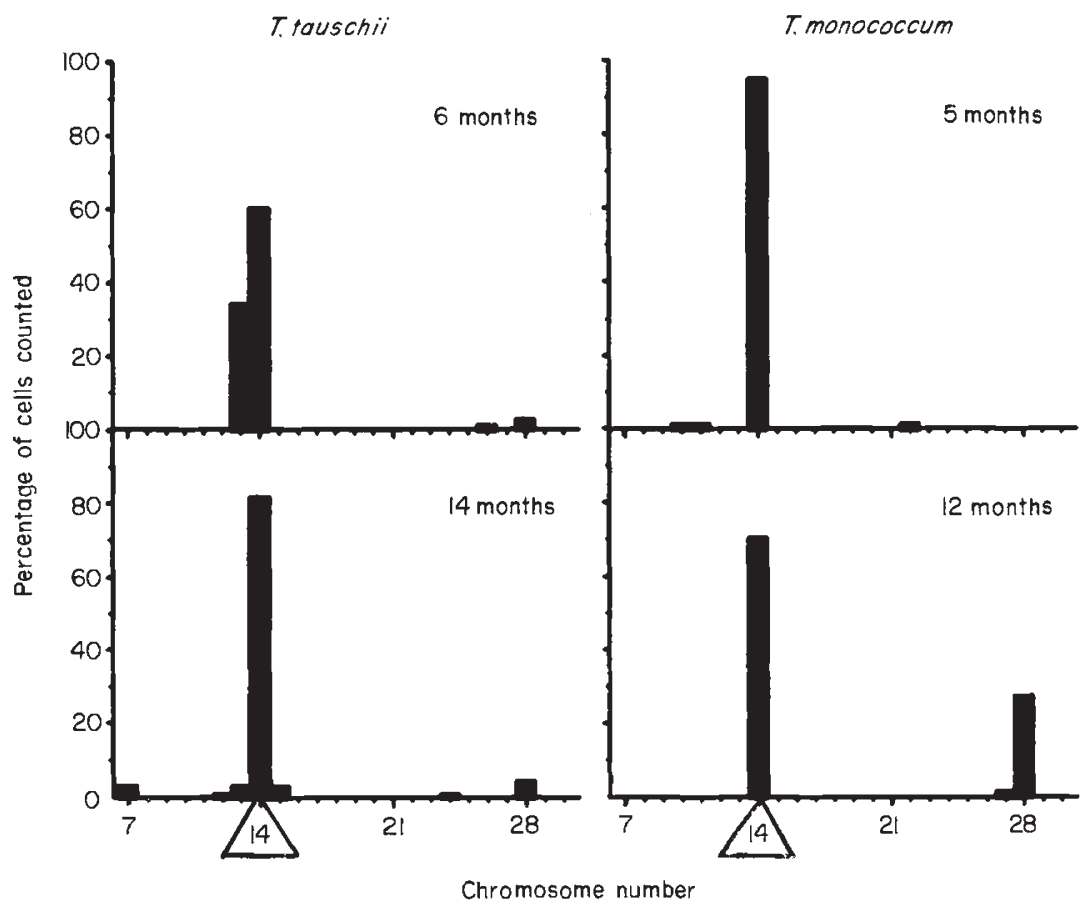


apparently, no cells possessed the normal number of chromosomes. Surprisingly, after 31 months in culture 41 per cent of cells counted had 42 chromosomes. In contrast samples taken from a line of the hexaploid cultivar Copain (referred to here as C82d) after 2 (Karp et al., 1987), 7 and 9 years, (Fig. 4) showed that the line continuously lost chromosomes through time. The modal numbers of chromosomes were 36, 29 and 26 respectively.

In all lines studied, except C82d, very few structural aberrations were seen (Fig. 5 and Table 1). All samples of C82d, however, contained a large percentage of cells carrying one or more structurally aberrant chromosomes. These included acrocentrics, dicentrics, fragments and many telocentrics (Table 1).

\section{Discussion}

Differences in chromosome stability were observed between cell suspensions of two diploids ( $T$. tauschii and $T$. monococcum), two tetraploids ( $T$. durum and $T$. dicoccum) and one hexaploid wheat (T. aestivum). The

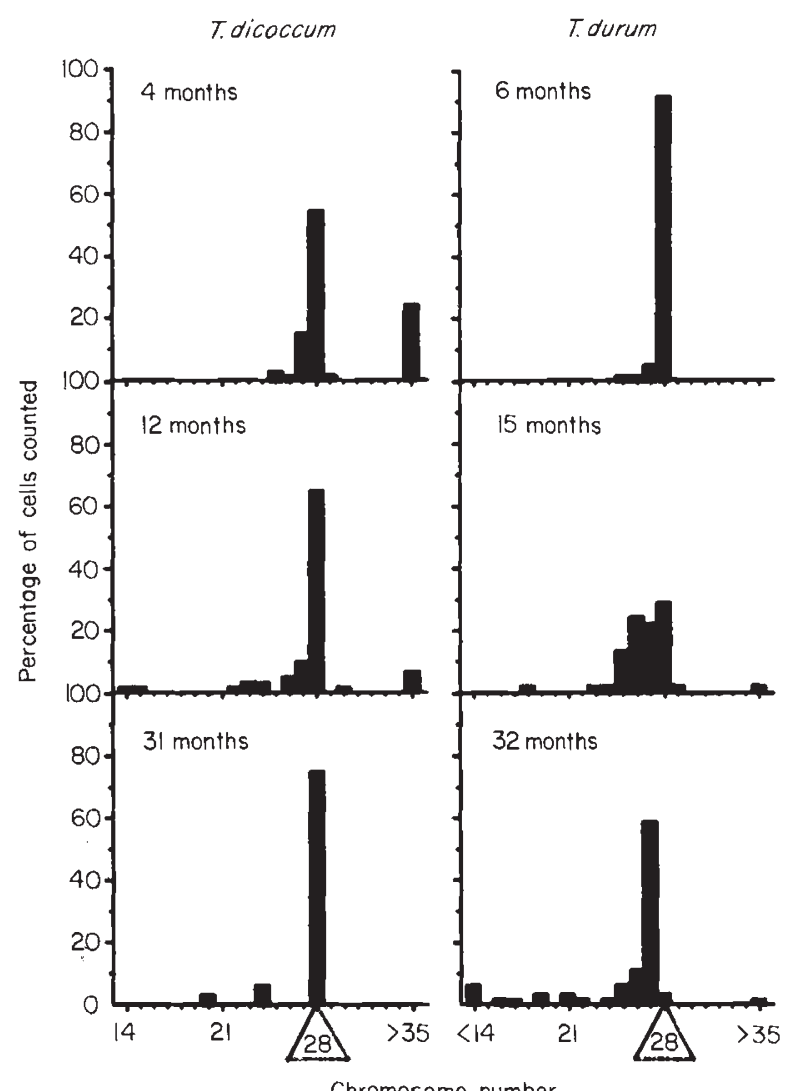

Fig. 2 Histograms of chromosome number per cell in cultured cells of the two tetraploid species; based on a minimum of 50 counts. Triangle indicates the euploid chromosome number. diploids were the most stable but, whilst the cells of the T. tauschii line remained predominantly diploid after 14 months in culture, the $T$. monococcum suspension showed a tendency for chromosome doubling. It will prove interesting to see whether the tetraploid cells become unstable, resulting in an accumulation of aneuploid cells with chromosome numbers between 14 and 28 , or whether they show more rapid growth than cells

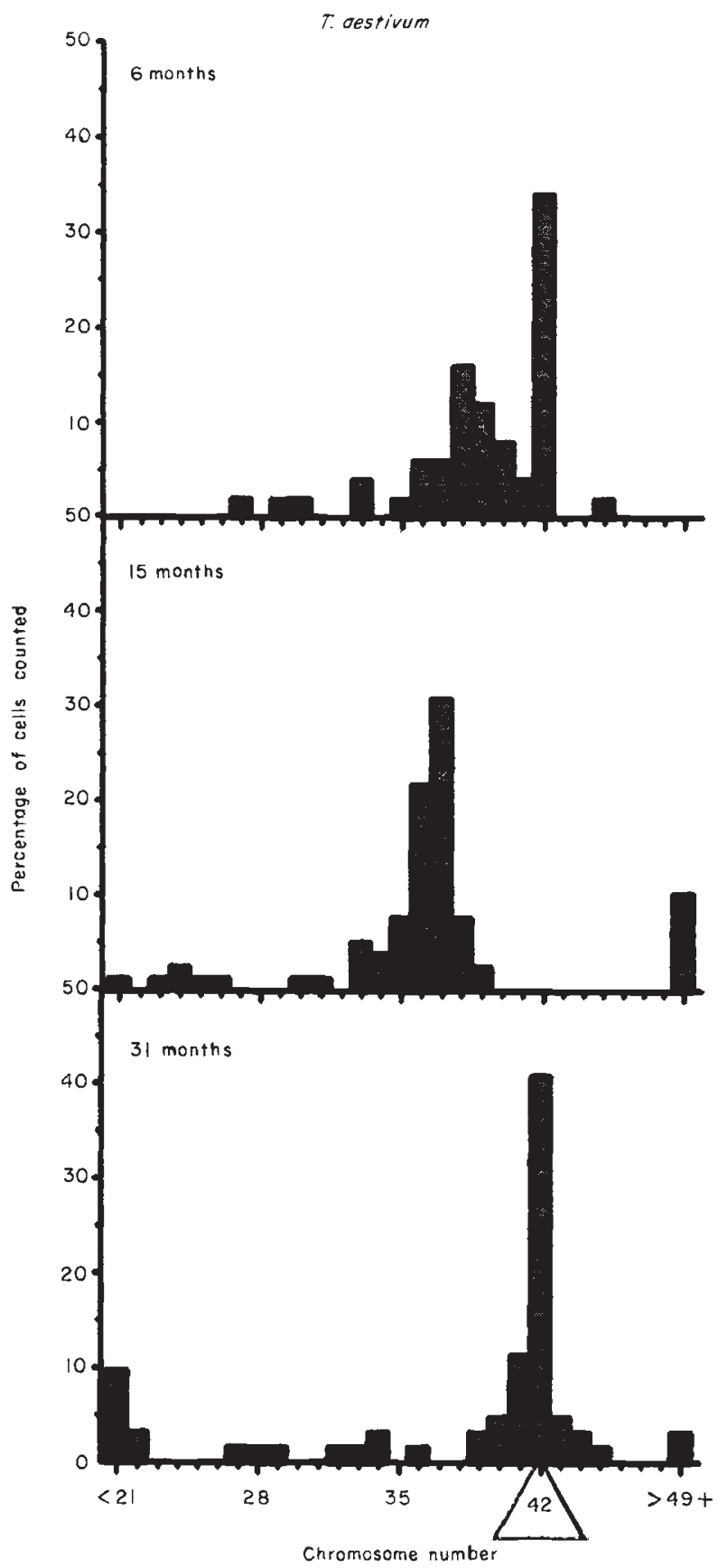

Fig. 3 Histograms of chromosome number per cell in cultured cells of Triticum aestivum cv. Sicco; based on a minimum of 50 counts. Triangle indicates the euploid chromosome number. 
Fig. 5 Cell spreads of (a) T. monococcum, after 5 months in culture, with an apparently normal diploid karyotype $(2 n=14)$; (b) $T$. durum after 31 months in culture with only 27 chromosomes; (c) T. aestivum, after 31 months in culture, with 38 chromosomes. There are no gross or obvious structural aberrations (scale bar $=10 \mu \mathrm{m})$.
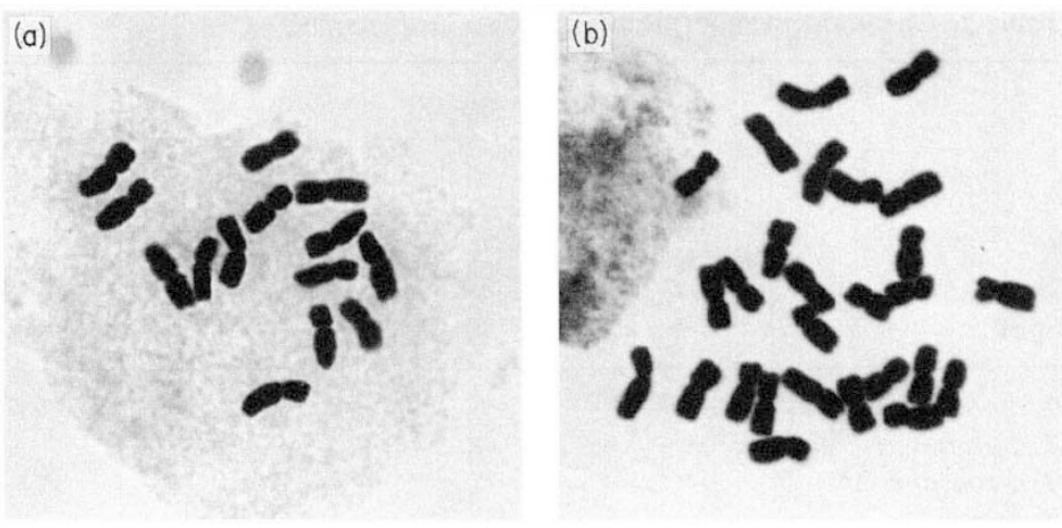

(c)

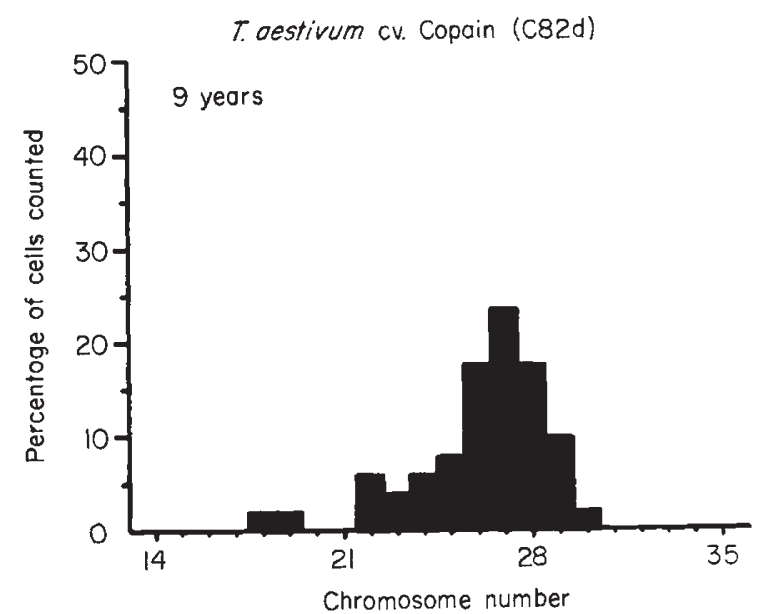

Fig. 4 Histogram of chromosome number in $T$. aestivum cv. Copain (C82d) after 9 years in culture; based on 52 counts. with 14 chromosomes leading to their predominance in the population, as suggested by Kao et al., (1970).

The two tetraploid lines also differed in stability. In the $T$. dicoccum line very little chromosome instability was observed throughout 31 months in culture, whereas the $T$. durum suspension experienced a distinct period of instability around 16 months and thereafter cells possessing the aneuploid constitution $2 n-1=27$ became predominant in the population.

After 6 months in culture the majority of cells in the suspension of $T$. aestivum had deviated from the normal chromosome number. This is in agreement with our previous report in cultivars Copain and Maris Butler (Karp et al., 1987) and with trends observed in several other cultivars of bread wheat $(M$. Winfield \& Schmidt, unpublished results). In cv. Sicco, however, karyologically normal cells were re-established as the majority of the population in the later stages of culture and, at 31 months, over 40 per cent of cells counted contained 42 chromosomes. A sample taken from the 
Table 1 Chromosome aberrations in the six suspensions

\begin{tabular}{|c|c|c|c|c|c|c|c|c|c|c|c|c|}
\hline \multirow[b]{4}{*}{ Species } & \multicolumn{12}{|c|}{ Chromosome structural aberrations } \\
\hline & \multirow{2}{*}{\multicolumn{3}{|c|}{$\frac{\text { Acrocentrics }}{\text { Time (months) }}$}} & \multirow{2}{*}{\multicolumn{3}{|c|}{$\frac{\text { Dicentrics }}{\text { Time (months) }}$}} & \multirow{2}{*}{\multicolumn{3}{|c|}{$\frac{\text { Fragments }}{\text { Time (months) }}$}} & \multirow{2}{*}{\multicolumn{3}{|c|}{$\frac{\text { Telocentrics }}{\text { Time (months) }}$}} \\
\hline & & & & & & & & & & & & \\
\hline & $4-6$ & $12-15$ & $30-32$ & $4-6$ & $12-15$ & $30-32$ & $4-6$ & $12-15$ & $30-32$ & $4-6$ & $12-15$ & $30-32$ \\
\hline T. monococcum & - & - & - & - & - & - & - & - & - & - & - & - \\
\hline T. tauschii & - & - & - & - & - & - & - & - & - & 4 & - & - \\
\hline T. dicoccum & - & - & 1 & - & - & - & - & - & - & 5 & - & - \\
\hline T. durum & - & - & 6 & - & - & 1 & - & 2 & - & - & - & 3 \\
\hline T. aestivum cv. Sicco & - & - & - & 1 & - & - & - & - & 2 & 4 & - & 1 \\
\hline T. aestivum cv. Copain* & & & 2 & 4 & 4 & 9 & 4 & 6 & 4 & & & 88 \\
\hline
\end{tabular}

*Results after 7 and 9 years in culture.

line at 25 months (data not shown) revealed 10 per cent of cells with 42 chromosomes, suggesting a gradual re-establishment of the euploid cells. Although most marked in the cv. Sicco line, the latest counts obtained had higher proportions of euploid (or neareuploid) cells in all the lines studied. This suggests that a burst of instabiiity occurs during the first months of culture, which is later modulated by the selective proliferation of some cells. Similar shifts have been reported in cell suspensions of potato (Pijnacker et al., 1986) and Haplopappus gracilis (Singh \& Harvey, 1975) and are thought to arise either through the differential viabilities of cells with different chromosome numbers or because some cell types divide more frequently than others. In addition, it should be noted that the cv. Sicco line was maintained over a period of time when relocation of our research group took place and technical assistance was changed. Some unintentional alteration in the sampling of cells during sub-culture may have resulted in increased selection for the normal cells. It is also possible that the re-established euploid cells may not have normal complements, as observed in endosperm cultures of rye grass (Norstog et al., 1969) and studies using $\mathrm{N}$ and $\mathrm{C}$ banding are currently under way to assess this.

The cell lines of Sicco and C82d behaved quite differently. Soon after initiation of the suspensions, cells in both lines began to lose chromosomes. In the C82d suspension, however, cells continued to lose chromosomes, while in the Sicco line, after an initial period when cells were losing chromosomes, cells with the normal chromosome number increased. In contrast, cells in the C82d suspension accumulated a large number of structurally aberrant chromosomes while Sicco did not. After C82d had been in culture for 2 years Karp et al. (1987) reported that 30 per cent of cells carried one or more aberrant chromosomes. In the Sicco suspension of an equivalent age only one cell out of 61 counted had aberrant chromosomes; two telocentrics and a fragment (Table 1). In an earlier study by Karp et al. (1987), the C82d suspension was 'recycled' by isolating protoplasts and then selecting the fastest growing protoplast-derived colonies to derive a new cell suspension. It is possible that this recycling strategy, aimed at increasing the frequency of protoplast divisions, acted as a selection pressure for fast dividing cells which, in turn, resulted in a high incidence of chromosome breakage and the proliferation of cells with diminished chromosome number. The more recently established cell suspensions used here were slower growing and it is interesting that not only were these lines less variant in terms of numerical chromosome changes but they also had fewer chromosome rearrangements.

These results indicate that the instability of wheat in culture is related to its allohexaploid nature and is under genetic control. The stability of the T. tauschii line in culture is interesting. It is known that diploids are less tolerant of chromosomal loss than polyploids and aberrations occurring in culture are consequently selected during regeneration (Constantin, 1981; Singh, 1986). However, in the T. tauschii cell cultures examined here, the chromosomes remained predominantly stable even though the lines had lost morphogenetic potential. This indicates that chromosome stability by itself is not sufficient for regenerative capacity. Similar results have been described in barley (Ziauddin \& Kasha, 1990), where cultures with the least instability had the greatest morphogenetic potential, but all the lines studied lost their ability to regenerate after 7 months, even though some had remained predominantly diploid. 
It would seem that two aspects of the genotype are important for maintenance of morphogenetic capacity. There is genetic control over morphogenetic response - a non-responsive genotype will not regenerate easily regardless of its cytological stability. Superimposed on this, different genotypes have different predispositions during the culture phase. In hexaploid bread wheat, instability frequently accumulates to levels which impede regenerative capacity, even in elite responsive lines (M. Schmidt, personal communication). Methods of consciously selecting only euploid hexaploid cells during culture have not yet been identified. As a result it is necessary to establish large numbers of lines to find one which is relatively stable and, even then, instability can accumulate with time. Conversely, as the diploid and tetraploids are more stable, attention might be more productively focused on screening for responsivenes and stability in the close relatives and progenitors of wheat. Our current emphasis is to select embryogenic lines which retain chromosome stability and some success has already been achieved with T. tauschii.

\section{Acknowledgements}

The help of Dr J.-W. Bang of Chungnam University, Seoul, Korea, and Miss Xia Jing, of the Beijing Academy of Agriculture and Forestry, Beijing, China in carrying out preliminary studies on the wheat lines is gratefully acknowledged. We also thank Miss S. H. Steele of the Biochemistry and Physiology Department, Rothamsted Experimental Station and Miss P. G. Owen of the Plant Sciences, Long Ashton Research Station, at the AFRC Institute of Arable Crops Research, U.K. for technical assistance. Mr Mark Winfield is supported by a SERC Case Studentship.

\section{References}

ABDUllaH, R., THOMPSON, J. A., KUSH, G. S. KAUSHIK, R. P. AND COCKING, E. 1989. Protoclonal variation in the seed progeny of plants regenerated from rice protoplasts. Plant Sci., 65, 97-102.

BAYLISS, M. w. 1980. Chromosomal variation in plant tissues in culture. Int. Rev. Cytol., 11A, 113-144.

CHANG, Y. F., WANG, W. C. WARFIELD, C. Y., NGUYEN, H. T. AND WONG, J. R. 1991. Plant regeneration from protoplasts isolated from long-term cell cultures of wheat (Triticum aestivum L.). Plant Cell Rep., 9, 611-614.

Constantin, M. J. 1981. Chromosome instability in cell and tissue cultures and regenerated plants. Env. Exp. Bot., 21, 359-368.

GALIBA, G., KOVÁCS, G. AND SUTKA, J. 1986. Substitution analysis of plant regeneration from callus culture in wheat. Plant Breed., 97, 261-263.
HARRIS, R., WRIGHT, M., BYRNE, M., VARNUM, J., BRIGHTWELL, B. AND SCHUBERT, K. 1988. Callus formation and plantlet regeneration from protoplasts derived from suspension cultures of wheat (Triticum aestivum L.). Plant Cell Rep., 7, 337-340.

HASHIM, Z. N., CAMBBELl, W. F. AND CARMAN, J. G. 1991. Normalization of the DNA content of telophase cells from wheat calli by nutrient modifications. Theor. Appl. Genet., 82, 413-416.

HE, D. G., YANG, Y. M. AND SCOTT, K. J. 1992. Plant regeneration from protoplasts of wheat (Triticum aestivum cv. Hartog). Plant Cell Rep., 11, 16-19.

HIGGins, P. AND MATHIAS, R. J. 1987. The effect of the 4B chromosome of hexaploid wheat on the growth and regeneration of callus cultures. Theor. Appl. Genet., 72, 439-444.

KAO, K. N., MiLleR, R. A., GAMBorG, O. L. AND hARVEY, B. L. 1970. Variation in chromosome number and structure in plant cells grown in suspension cultures. Can. J. Genet. Cytol., 12, 279-301.

KARP, A. 1991. On the current understanding of somaclonal variation. Oxford Surv. Plant Mol. Cell. Biol., 7, 1-58.

KARP, A. AND MADDOCK, S. E. 1984. Chromosome variation in wheat plants regenerated from cultured immature embryos. Theor. Appl. Genet., 67, 249-255.

KARP, A., NELSON, R. S., THOMAS, E. AND BRIGHT, S. W. J. 1982. Chromosome variation in protoplast-derived potato plants. Theor. Appl. Genet., 63, 265-272.

KARP, A., WU, Q. S., STEELE, S. H. AND JONES, M. G. K. 1987. Chromosome variation in dividing protoplasts and cell suspensions of wheat. Theor. Appl. Genet., 74, 140-146.

LARKIN, P. J. AND SCOWCROFT, W. R. 1981. Somaclonal variation - a novel source of variability from cell cultures for plant improvement. Theor. Appl. Genet., 60, 197-214.

LAZAR, M. D., COLliNS, G. B. AND VIAN, w. E. 1983. Genetic and environmental effects on the growth and differentiation of wheat somatic cell cultures. J. Hered., 74, 353-357.

LI, Z.-Y., GUANG-MIN, X., HUI-MIN, C. AND GUANG-QIN, G. 1992. Plant regeneration from protoplasts derived from embryogenesis suspension cultures of wheat (Triticum aestivum L.). J. Plant Physiol. 139, 714-718.

MADDOCK, S. E., LANCASTER, R., RISIOTT, R. AND FRANKLIN, J. 1983. Plant regeneration from cultured immature embryos and inflorescences of 25 cultivars of wheat (Triticum aestivum). J. Expt. Bot., 34, 915-926.

MURASHige, T. AND NAKANO, R. 1967. Chromosome complement as a determinant of the morphological potential of tobacco cells. Am. J. Bot., 54, 963-970.

MURASHIGE, T. AND SKoog, F. 1962. A revised medium for rapid growth and bioassays with tobacco tissue culture. Physiol. Planta., 15, 473-497.

NORSTOG, K., WENDELl, E., WALl, E. AND HOWARD, G. P. 1969. Cytological characteristics of ten-year-old rye-grass endosperm tissue cultures. Bot. Gaz., 130, 83-86.

PIJNACKER, L. P., HERMELINK, J. H. M. AND FERWERDA, M. A. 1986. Variability of DNA content and karyotype in cell cultures of an interdihaploid Solanum tuberosum. Plant Cell Rep., $5,43-46$.

SINGH, B. D. AND HARVEY, B. L. 1975. Selection for diploid cells in suspension cultures of Happlopappus gracilis. Nature, 253,453 . 
SINGH, R. J. 1986. Chromosomal variation in immature embryo derived calluses of barley (Hordeum vulgare L.). Theor. Appl. Genet., 72, 710-716.

VASIL, V., REDWAY, F. AND VASIL, I. K. 1990. Regeneration of plants from embryogenic suspension culture protoplasts of wheat (Triticum aestivum L.). Bio/Technol., 8, 429-434.
ZIAUDDIN, A. AND KASHA, K. J. 1990. Long-term callus cultures of diploid barley (Hordeum vulgare). II. Effects of auxins on chromosomal status of cultures and regeneration of plants. Euphytica, 48, 279-286. 